\title{
Comparative Study of Influences of Gamma Rays on Calix[4]Arene and 25,27-di(4-Nitrobenzyl)-26,28-Dihydroxycalix[4]Arene: EPR Study
}

\author{
Y. Ceylan*, K. Usta, N. Ceylan, A. Usta and Y. Koc \\ Selcuk University, Department of Physics, Konya, Turkey
}

\begin{abstract}
In the present study, calix[4]arene and its derivate 25,27-di(4-nitrobenzyl)-26,28-dihydroxycalix[4]arene were irradiated for 72 hours by ${ }^{60} \mathrm{Co}$ gamma rays at dose rate of $0.720 \mathrm{kGy} / \mathrm{h}$. These irradiated samples were analyzed by EPR method and it was found that one type of radical was produced in calix[4]arene, and two type of radicals were produced in 25,27-di(4-nitrobenzyl)-26,28-dihydroxycalix[4]arene. The measurements were performed in the temperature range of 273-400 K using x-band EPR spectrometer. It was observed that the spectra, obtained from two samples, have very weak temperature dependence. Hyperfine and $g$ parameters were calculated for two samples.
\end{abstract}

DOI: $10.12693 /$ APhysPolA.132.1211

PACS/topics: 87.66.Uv, 36.20.Kd, 39.30.+w, 33.35.+r

\section{Introduction}

Calixarenes composed of aromatic rings and phenolic hydroxyl groups are used as the hosts of inclusion compounds [1]. These compounds, appropriately designed, have exhibited a large variety of functions, such as selective complexing agents for metal ions and catalysts [2]. Calixarenes are macrocycles with a high degree of preorganization. Macrocycles based upon calix[4]arenes have been utilized as effective frameworks $[3,4]$. In such macrocycles, four triphenylmethyl radicals are connected in the chain formed by cross-conjugated p-systems in the cycle in which the radicals are coupled through $\mathrm{m}$ phenylene [5-7].

It is known that irradiation changes a number of physical and chemical properties of the materials, such as electrical resistivity, magnetic susceptibility. The irradiationinduced materials may be used in new research fields, such as biosensors and electronic devices. Therefore, it is important to identify radical structures produced by irradiation. EPR is a powerful spectroscopic method for detecting radicals in the materials [7-18]. In this study, Calix[4]arene, labeled calix[4]arene(1), and 25,27-di(4-nitrobenzyl)-26,28-dihydroxycalix[4]arene, labeled calix[4]arene(2), were exposed to gamma rays and then radical structures of these calix[4]arenes were evaluated by EPR method.

\section{Materials and methods}

All solvents and compounds were commercially graded reagents and they were used without further

*corresponding author; e-mail: yceylan@selcuk.edu.tr purification. Melting points were measured using an Electrothermal IA9100 digital melting point apparatus in capillaries sealed under nitrogen. 1H NMR spectra were referenced to tetramethylsilane (TMS) at $0.00 \mathrm{ppm}$ as internal standard solution and recorded at room temperature $\left(25 \pm 1^{\circ} \mathrm{C}\right)$ using a Bruker $400 \mathrm{MHz}$ spectrometer. IR spectra were recorded by a Mattson 1000 FTIR spectrometer. UV-vis spectra were obtained using a Shimadzu 1601 UV-Visible recording spectrophotometer. The EPR spectra were recorded by using Bruker EMX 081 spectrometer (x-band, Germany)

\subsection{Preparation of the ligand}

p-tert-Butylcalix[4]arene and calix[4]arene(1) were synthesized as described in the literature $[19,20]$.

\subsection{Synthesis of 25,27-di(4-nitrobenzyl)-26,28- dihydroxycalix[4]arene(2) [21]}

A mixture of p-tert-butylcalix[4] arene $(5.0 \mathrm{~g}$, $11.79 \mathrm{mmol})$, anhydrous $\mathrm{K}_{2} \mathrm{CO}_{3}(1.85 \mathrm{~g}, 13.45 \mathrm{mmol})$ and pnitrobenzyl bromide (5.06 g, $23.442 \mathrm{mmol}$ ) in $\mathrm{CH}_{3} \mathrm{CN}(80 \mathrm{ml})$ was refluxed for $20 \mathrm{~h}$. The solvent was removed under reduced pressure. The mixture was treated with $\mathrm{CH}_{3} \mathrm{Cl}(100 \mathrm{ml})$ and filtered. The filtrate was concentrated under reduced pressure $(20 \mathrm{ml})$. Then $\mathrm{CH}_{3} \mathrm{OH}(50 \mathrm{ml})$ was added and the pale white crystals appeared gradually. After a few hours the crystals were vacuum filtered and washed with cold methanol to give $4.5 \mathrm{~g}(90.0 \%)$ of the pure compound 1. Melting point 245-248 ${ }^{\circ}$ C. FTIR $\left(\mathrm{KBr}, \mathrm{cm}^{-1}\right): 3374,3112,3025$, 2920, 2856, 1607, 1522, 1466, 1346, 1299, 1267, 1247, 1193, 1030, 906, 841, 758, 737, 608, 572, 465. 1H-NMR $\left(400 \mathrm{MHz}, \mathrm{CDCl}_{3}, 250^{\circ} \mathrm{C}\right): \delta=3.4(\mathrm{~d}, 4 \mathrm{H}), 4.2(\mathrm{~d}, 4 \mathrm{H})$, $5.2(\mathrm{~s}, 4 \mathrm{H}), 6.5(\mathrm{q}, 4 \mathrm{H}), 6.8(\mathrm{~d}, 4 \mathrm{H}), 6.8(\mathrm{~d}, 4 \mathrm{H}), 7.6$ $(\mathrm{s}, 2 \mathrm{H}), 7.9(\mathrm{~d}, 4 \mathrm{H}), 8.07(\mathrm{~d}, 4 \mathrm{H})$. Elemental analysis: 
calculated for $\mathrm{C}_{42} \mathrm{H}_{34} \mathrm{~N}_{2} \mathrm{O}_{8}$ : C (72.61\%), $\mathrm{H}(4.93 \%), \mathrm{N}$ (4.03\%), O (18.42\%); Found: C (72.63\%), H (4.92\%), N $(4.02 \%)$, O $(18.43 \%)$.

\subsection{EPR measurements}

The polycrystal forms of the calix[4]arene(1) and calix[4]arene(2) samples were produced by slow evaporation of ethyl acetate concentrated solutions. These samples were irradiated for 72 hours by ${ }^{60} \mathrm{Co} \gamma$-ray source with dose rate of $0.720 \mathrm{kGy} /$ hour. The spectrometer was set as follows: the microwave power was $2 \mathrm{~mW}$, the modulation frequency was $100 \mathrm{kHz}$. The temperature measurements were performed between $273 \mathrm{~K}$ and $400 \mathrm{~K}$ using temperature control unit of the spectrometer.

\section{Results and discussion}

Calix[4]arene(1) and calix[4]arene(2) samples were irradiated for 72 hours to compare the structural changes. The spectra were recorded in the temperature range of $273-400 \mathrm{~K}$. The numbers and the intensity values of the lines in the spectra of calix[4]arene(1) and calix[4]arene(2) did not change with increasing temperature (Fig. 1).

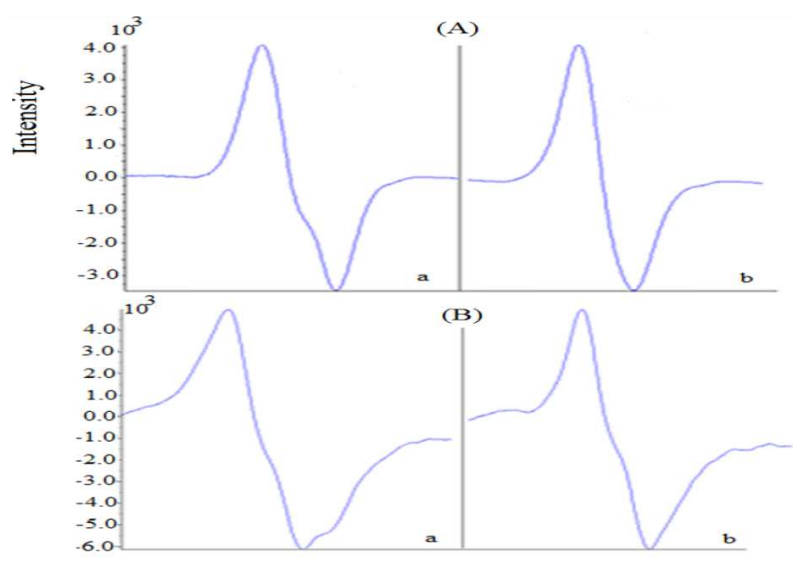

Fig. 1. EPR line at $273 \mathrm{~K}$ (a), $400 \mathrm{~K}$ (b) for calix[4]arene(1) (A) and calix[4] $\operatorname{arene}(2)$ (B).

If the spectra and the molecular structure of ca$\operatorname{lix}[4] \operatorname{arene}(1)$ are taken into account, it is seen that one unpaired electron was produced by scission of $\mathrm{O}-\mathrm{H}$ bond and the electron is localized on oxygen atom and interacts with hydrogen atom. Hence, the spectrum was split to 1:1 intensity ratios. The recorded spectra from calix[4]arene(2) are quite complex, and were deeply analyzed. Two lines and an additional small line in the side of spectrum of calix [4]arene(2) were observed. It was found that there are different distances between the two lines and the side line. From this we have inferred that two radicals were created. First unpaired electron was produced by scission of $\mathrm{O}-\mathrm{H}$ bond. The unpaired electron is localized on oxygen atom and interacts with hydrogen atom. Hence, the spectrum was split to 1:1 intensity ratios. Another unpaired electron was produced by removal of one electron from the paired electrons on the nitrogen atom. It is localized on the nitrogen atom. Interaction of these calix[4]arene samples with gamma rays was explained as shown in Fig. 2.

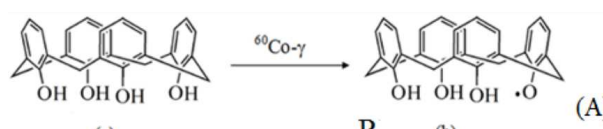

(a) $\mathrm{R} \quad$ (b)

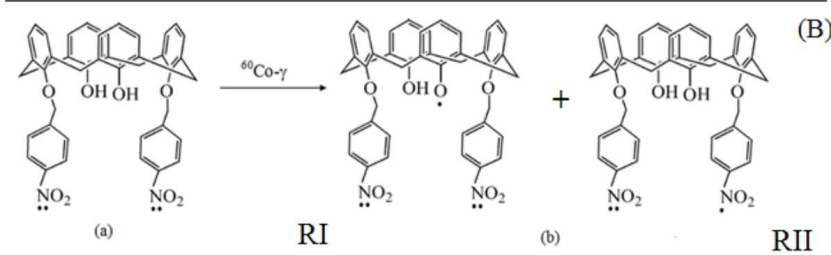

Fig. 2. The molecular structures (a) and radical structures (b) for calix[4]arene(1) (A) and ca$\operatorname{lix}[4] \operatorname{arene}(2)(\mathrm{B})$.

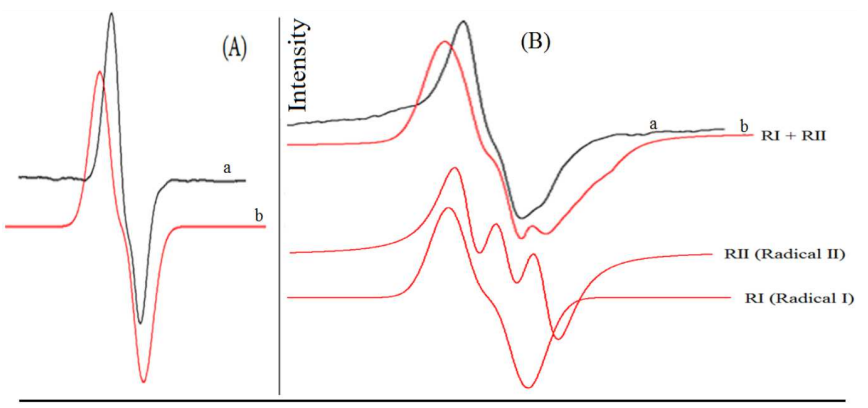

Gauss (G)

Fig. 3. The experimental EPR spectra (a) and their simulations (b) for calix[4]arene(1) (A) andcalix[4]arene(2) (B).

The radical in calix[4]arene(1) was labeled by $\mathrm{R}$; the radicals on calix[4]arene(2) were labeled by RI and RII (Fig. 2). These results were also verified by computer simulations (Fig. 3). The EPR parameters of these radical structures are shown in Table I.

In additional, unpaired electron concentrations (number of unpaired spins per gram) were calculated for calix[4]arene(1) and calix[4]arene(2) (Fig. 4). Figure 4 shows that although the unpaired electron concentration in calix[4]arene(2) had the smallest value at room temperature, it increased rapidly above the room temperature. The unpaired electron concentration in calix[4]arene(1) was stable against the temperature.

For the purpose of determining the stability of the radicals, EPR measurements were performed at regular intervals for two days. The obtained results show that the radical structures in calix[4]arene(1) and calix[4]arene(2) are stable. Also, it was observed that the color of the irradiated calix[4]arene(2) had changed from white to yellow at room temperature, but the color of the irradiated calix[4]arene(1) did not change. 
TABLE I

EPR parameters of the radical structures of the calix[4]arenes.

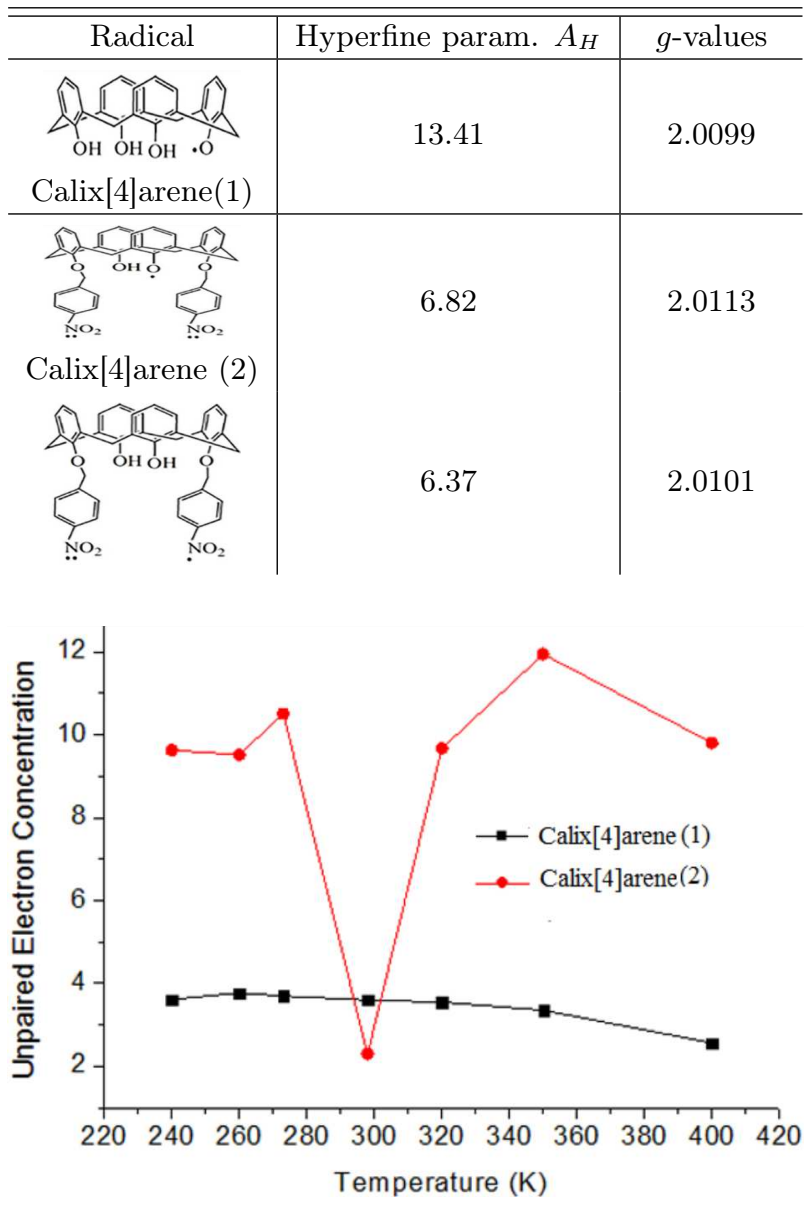

Fig. 4. Temperature dependence of the unpaired spin concentration between 120 and $450 \mathrm{~K}$ for calix[4]arene(1) (A) and calix[4]arene(2) (B) samples irradiated for 72 hours.

\section{Conclusions}

One type of radical was produced in calix[4]arene labeled calix[4]arene(1), two types of radicals were produced in 25,27-di(4-nitrobenzyl)-26,28-dihydroxycalix[4]arene labeled calix[4]arene(2). The EPR spectra were recorded in the temperature range of $273-400 \mathrm{~K}$. The numbers and the intensity values of the lines in the spectra of calix[4]arene(1) and calix[4]arene(2) did not change with the increasing temperature $(273-400 \mathrm{~K})$. It was also observed that the color of the irradiated calix[4]arene(2) has changed from white to yellow at room temperature, but the color of the irradiated calix[4]arene(1) did not change. According to the results obtained from analysis of the spectra, it can be said that calix[4]arene derivatives are less resistant to irradiation. We hope that the present study on characterization of the calix[4]arenes [22] will develop new research fields in chemistry, physics, etc.

\section{Acknowledgments}

This work is partially supported by the BAP office of Selcuk University.

\section{References}

[1] C.D. Gutsche, Calixarenes Revisited, Royal Society of Chemistry, Cambridge 1998. p. 112.

[2] H. Deligoz, J. Inclusion Phenom. Macrocyclic Chem. 55, 197 (2006).

[3] A. Rajca, S. Rajca, R. Padmakumar, Angew. Chem. Int. Ed. Engl. 33, 2091 (1994).

[4] A. Rajca, Adv. Phys. Org. Chem. 40, 153 (2005).

[5] S. Fang, M.S. Lee, D.A. Hrovat, W.A. Borden, J. Am. Chem. Soc. 117, 6727 (1995).

[6] P.M. Lahti,Magnetic Properties of Organic Materials, Marcel Dekker, New York 1999.

[7] K. Itoh, M. Kinoshita, Molecular Magnetism, Gordon and Breach, Amsterdam 2000.

[8] E. Aras, B. Asik, M. Eken, M. Birey, Radiat. Eff. Defects S. 161, 373 (2006).

[9] M.A. Merdan, B. Asik, M. Birey, E. Aras, Radiat. Eff. Defects S. 167, 179 (2012).

[10] O. Karatas, E. Aras, J. Mol. Struct. 1027, 49 (2012).

[11] K. Usta, Y. Ceylan, A. Usta, N. Ceylan, E. Aras, Acta Phys. Pol. A 130, 178 (2016).

[12] Y. Celik, E. Bozkurt, B. Karabulut, N. Dege, Acta Phys. Pol. A 130, 163 (2016).

[13] Y. Ceylan, K. Usta, H. Yumurtaci Aydogmus, A. Usta, N. Ceylan, E. Aras, Acta Phys. Pol. A 130, 184 (2016).

[14] Y. Ceylan, H. Yumurtac1 Aydogmus, K. Usta, A. Usta, N. Ceylan, H. Yılmaz, Acta Phys. Pol. A 130, 167 (2016)

[15] Y. Ceylan, A. Usta, K. Usta, F. Kont Cobankara, C. Yildirim, M. Birey, Acta Phys. Pol. A 128, B-479 (2015).

[16] Y. Ceylan, K. Usta, A. Usta, E. Maltas, S. Yildiz, Acta Phys. Pol. A 128, B-483 (2015).

[17] A. Usta, H. Cingilli Vural, K. Usta, E. Aras, Y. Ceylan, A. Ozmen, J. Phys. Org. Chem. 24, 635 (2011).

[18] Y. Ceylan, K. Usta, A. Usta, H. Yumurtaci Aydogmus, A. Guner, J. Mol. Struct. 1100, 180 (2015).

[19] O.O. Karakus, H. Deligoz, J. Incl. Phenom. Macrocyclic Chem. 61, 289 (2008).

[20] H. Deligoz, Supramol. Chem. 15, 317 (2003).

[21] H.K. Alpoguz, A. Kaya, H. Deligoz, Sep. Sci. Technol. 41, 1155 (2006).

[22] K. Usta, O. O.Karakus, A. Usta, H. Deligoz, Magn. Reson. Chem. 51, 671 (2013). 